Pacific Journal of Mathematic

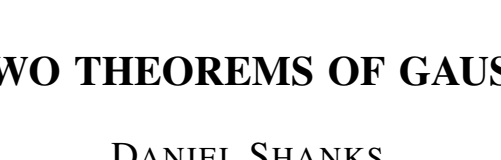




\section{TWO THEOREMS OF GAUSS}

\section{DANIEL SHANKS}

The purpose of this note is to show that two famous theorems of Gauss can be derived from a common source. The theorems alluded to are the following:

Theorem 1. (The triangular-exponent identity)

$$
\prod_{s=1}^{\infty} \frac{1-x^{2 s}}{1-x^{2 s-1}}=\sum_{s=1}^{\infty} x^{s(s-1) / 2} .
$$

Theorem 2. (The evaluation of Gauss sums)

$$
\sum_{s=0}^{m-1} e^{2 \pi i s^{2} / m}=\left\{\begin{array}{lll}
\sqrt{m} & \text { for } & m \equiv 1(\bmod 4) \\
i \sqrt{m} & \text { for } & m \equiv 3(\bmod 4) .
\end{array}\right.
$$

Both these results will be obtained as consequences of the following identity previously stated by the author [2] without proof.

A finite identity.

Theorem. If $P_{0}=1$ and

$$
P_{n}=\prod_{s=1}^{n}\left(\frac{1-x^{2 s}}{1-x^{2 s-1}}\right)
$$

for $n=1,2, \cdots$, then

$$
A_{n}=\sum_{s=0}^{n-1} \frac{P_{n}}{P_{s}} x^{s(2 n+1)}=\sum_{s=1}^{2 n} x^{s(s-1) / 2}=S_{n}
$$

and

$$
A_{n}^{\prime}=\sum_{s=1}^{n} \frac{P_{n}}{P_{s}} x^{s(2 n+1)}=\sum_{s=1}^{2 n+1} x^{s(s-1) / 2}=S_{n}^{\prime} .
$$

Proof. We readily verify that

$$
\begin{aligned}
\left(1-x^{2 n}\right) x^{s(2 n+1)}= & \left(1-x^{2 n-1}\right) x^{s(2 n-1)}+\left(1-x^{2 s+1}\right) x^{(s+1)(2 n-1)} \\
& -\left(1-x^{2 s}\right) x^{s(2 n-1)},
\end{aligned}
$$

and by multiplying by $\frac{P_{n-1}}{P_{s}\left(1-x^{2 n-1}\right)}$ we find

Received February 5, 1958, and in revised form May 7, 1958. 


$$
\frac{P_{n}}{P_{s}} x^{s(2 n+1)}=\frac{P_{n-1}}{P_{s}} x^{s([2 n-1]+1)}+\alpha_{s, n}-\beta_{s, n}
$$

where

$$
\alpha_{s, n}=\frac{1-x^{2 s+1}}{1-x^{2 n-1}} \frac{P_{n-1}}{P_{s}} x^{(s+1)(2 n-1)}
$$

and

$$
\beta_{s, n}=\frac{1-x^{2 s}}{1-x^{2 n-1}} \frac{P_{n-1}}{P_{s}} x^{s(2 n-1)} .
$$

Now

$$
\beta_{s+1, n}=\alpha_{s, n} \quad(\text { for } s=0,1, \cdots, n-2)
$$

and since, further,

$$
\beta_{0, n}=0 \text { and } \alpha_{n-1, n}=x^{n(2 n-1)},
$$

by summing (4) from $s=0$ to $s=n-1$ we obtain :

$$
A_{n}=A_{n-1}+x^{(n-1)(2 n-1)}+x^{n(2 n-1)} \text {. }
$$

But this may be written $A_{n}-A_{n-1}=S_{n}-S_{n-1}$, and by induction

$$
A_{n}-S_{n}=A_{1}-S_{1}=\frac{1-x^{2}}{1-x}-(1+x)=0 .
$$

This proves (3) and by adding $x^{n(2 n+1)}$ to both sides we verify ( $\left.3^{\prime}\right)$.

Gauss' triangular exponent Theorem (1), now follows at once from (3).

Proof of Theorem 1. The leading term in $A_{n}$ (that is $s=0$ in the left side of eq. 3$)$ is $P_{n}$. Since the remaining terms $(s=1,2, \cdots$, $n=1)$ are of order $x^{2 n+1}$ and higher, the power series of the function $P_{n}(x)$ must agree with that of $S_{n}(x)$ at least to terms of order $x^{2 n}$. By induction the function $P_{\infty}$ must have the power series $S_{\infty}$ and this proves (1).

Proof of Theorem 2. The magnitude of

$$
G=\sum_{s=0}^{m-1} e^{2 \pi t s^{2} / m}
$$

for any odd integer $m$ is given by $|G|=\sqrt{m}$. This is easily shown, $[1$, p. 163], by multiplying $G$ by its complex conjugate. The real difficulty in Theorem (2) is to show that $G$ is positive real or positive imaginary according as $m \equiv 1$ or $m \equiv 3(\bmod 4)$. But the identity (3) enables us to do this without undue computation.

First we write $x=v^{2}$ where $v=e^{i q}$. Then 


$$
P_{n}=v^{n} \prod_{s=1}^{n}\left(\frac{v^{2 s}-v^{-2 s}}{v^{2 s-1}-v^{1-2 s}}\right)
$$

and if

$$
Q_{0}=1, \quad Q_{n}=\prod_{s=1}^{n}\left(\frac{\sin 2 s \theta}{\sin (2 s-1) \theta}\right)
$$

we may write

$$
\begin{aligned}
& S_{n}=\sum_{s=1}^{2 n} v^{s(s-1)}=\sum_{s=1}^{n-1} v^{n+s(4 n+1)} \frac{Q_{n}}{Q_{s}} \\
& S_{n}^{\prime}=\sum_{s=1}^{2 n+1} v^{s(s-1)}=\sum_{s=0}^{n} v^{n+s(4 n+1)} \frac{Q_{n}}{Q_{s}} .
\end{aligned}
$$

Now for any odd integer, $m=2 N+1$, if $\theta=2 \pi / m$ we have

$$
v^{2 N}=v^{-1}
$$

and thus

$$
\begin{aligned}
G=\sum_{s=0}^{m-1} v^{s^{2}} & =\sum_{s=-N}^{+N} v^{(N+s)^{2}}=v^{N^{2}} \sum_{s=-N}^{+N} v^{s(s-1)} \\
& =v^{N^{2}}\left[\sum_{s=1}^{N} v^{s(s-1)}+\sum_{s=1}^{N+1} v^{s(s-1)}\right] .
\end{aligned}
$$

Therefore if $m=4 n+1$ and $N=2 n$,

$$
G=\sum_{s=0}^{n-1} v^{(n+s)(4 n+1)} \frac{Q_{n}}{Q_{s}}+\sum_{s=0}^{n} v^{(n+s)(4 n+1)} \frac{Q_{n}}{Q_{s}}
$$

But $v^{4 n+1}=1$ and $Q_{s}=$ positive real for $s=0,1, \cdots, n$ so that

$$
G=+\sqrt{m}
$$

And, if $m=4 n+3$ and $N=2 n+1$, then

$$
\begin{aligned}
G & =v^{N^{2}}\left[\sum_{s=0}^{n} v^{n+s(4 n+1)} \frac{Q_{n}}{Q_{s}}+\sum_{s=0}^{n} v^{n+1+s(4 n+5)} \frac{Q_{n+1}}{Q_{s}}\right] \\
& =\sum_{s=0}^{n} v^{(4 n+3)(n+s)}\left[v^{2 n+1-2 s} \frac{Q_{n}}{Q_{s}}+v^{2 n+2+2 s} \frac{Q_{n+1}}{Q_{s}}\right] .
\end{aligned}
$$

But now $v^{4 n+3}=1$ and

$$
Q_{n+1}=\frac{\sin [(2 n+2) \theta]}{\sin [(2 n+1) \theta]} Q_{n}=-Q_{n}
$$

and thus 
( 7 )

$$
G=2 i \sum_{s=0}^{n} \sin [(2 n+1-2 s) \theta] \frac{Q_{n}}{Q_{s}}
$$

which is positive imaginary. Therefore

$$
G=+i \sqrt{m} \quad m \equiv 3(\bmod 4) .
$$

\section{REFERENCES}

1. E. Landau, Aus der elementaren Zahlentheorie, Chelsea, New York, 1946.

2. D. Shanks, A short proof on an identity of Euler, Proc. Amer. Math. Soc. 2 (1951), 749 .

DAVID TAYLOR MODEL BASIN

WASHINGTON 7, D. C. 


\section{PACIFIC JOURNAL OF MATHEMATICS}

\section{EDITORS}

David Gilbarg

Stanford University

Stanford, California

R. A. Beaumont

University of Washington

Seattle 5, Washington

\author{
A. L. Whiteman
}

University of Southern California

Los Angeles 7, California

E. G. Straus

University of California

Los Angeles 24, California

\section{ASSOCIATE EDITORS}

\author{
E. F. BECKENBACH \\ C. E. BURGESS \\ M. HALL \\ E. HEWITT
}

\author{
A. HORN \\ V. GANAPATHY IYER \\ R. D. JAMES \\ M. S. KNEBELMAN
}

L. NACHBIN
I. NIVEN
T. G. OSTROM
H. L. ROYDEN

M. M. SCHIFFER

G. SZEKERES

F. WOLF

K. YOSIDA

\section{SUPPORTING INSTITUTIONS}

\author{
UNIVERSITY OF BRITISH COLUMBIA \\ CALIFORNIA INSTITUTE OF TECHNOLOGY \\ UNIVERSITY OF CALIFORNIA \\ MONTANA STATE UNIVERSITY \\ UNIVERSITY OF NEVADA \\ OREGON STATE COLLEGE \\ UNIVERSITY OF OREGON \\ UNIVERSITY OF SOUTHERN CALIFORNIA
}

\author{
STANFORD UNIVERSITY \\ UNIVERSITY OF UTAH \\ WASHINGTON STATE COLLEGE \\ UNIVERSITY OF WASHINGTON \\ AMERICAN MATHEMATICAL SOCIETY \\ CALIFORNIA RESEARCH CORPORATION \\ HUGHES AIRCRAFT COMPANY \\ THE RAMO-WOOLDRIDGE CORPORATION
}

Mathematical papers intended for publication in the Pacific Journal of Mathematics should be typewritten (double spaced), and the author should keep a complete copy. Manuscripts may be sent to any of the editors. All other communications to the editors should be addressed to the managing editor, E. G. Straus at the University of California, Los Angeles 24, California.

50 reprints per author of each article are furnished free of charge; additional copies may be obtained at cost in multiples of 50 .

The Pacific Journal of Mathematics is published quarterly, in March, June, September, and December. The price per volume (4 numbers) is $\$ 12.00$; single issues, $\$ 3.50$. Back numbers are available. Special price to individual faculty members of supporting institutions and to individual members of the American Mathematical Society: $\$ 4.00$ per volume; single issues, $\$ 1.25$.

Subscriptions, orders for back numbers, and changes of address should be sent to Pacific Journal of Mathematics, 2120 Oxford Street, Berkeley 4, California.

Printed at Kokusai Bunken Insatsusha (International Academic Printing Co., Ltd.), No. 6, 2-chome, Fujimi-cho, Chiyoda-ku, Tokyo, Japan.

\section{PUBLISHED BY PACIFIC JOURNAL OF MATHEMATICS, A NON-PROFIT CORPORATION}

The Supporting Institutions listed above contribute to the cost of publication of this Journal, but they are not owners or publishers and have no responsibility for its content or policies. 


\section{Pacific Journal of Mathematics}

\section{Vol. 8, No. 3 \\ May, 1958}

Michael Israel Aissen, A set function defined for convex plane domaines... . 383

Robert Ellis, Distal transformation groups ................... 401

Ciprian Foias, On a commutative extension of a commutative Banach algebra ....................................... 407

Jerry William Gaddum, Linear inequalities and quadratic forms ......... 411

Allen A. Goldstein and Elliott Ward Cheney, Jr., A finite algorithm for the solution of consistent linear equations and inequalities and for the Tchebycheff approximation of inconsistent linear equations...........

William L. Hart and T. S. Motzkin, Proof of the fundamental theorem on implicit functions by use of composite gradient corrections .......... 429

Henry Berge Helson, Conjugate series and a theorem of Paley .......... 437

Wu-Chung Hsiang, Abelian groups characterized by their independent subsets....................................... 447

John W. Lamperti, On the isometries of certain function-spaces ........ 459

Karel DeLeeuw and Walter Rudin, Extreme points and extremum problems

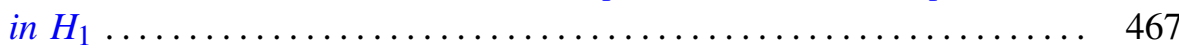

Eugene Lukacs, Some extensions of a theorem of Marcinkiewicz........ 487

George W. Mackey, Multiplicity free representations of finite groups ..... 503

Eben Matlis, Injective modules over Noetherian rings ............. 511

John William Neuberger, Continuous products and nonlinear integral equations

Lawrence Edward Payne and Hans F. Weinberger, New bounds for solutions of second order elliptic partial differential equations...

William T. Reid, A Prüfer transformation for differential systems ........ 575

Howard L. Rolf, The free lattice generated by a set of chains ...

K. M. Saksena, Inversion and representation theorems for a generalized

Laplace integral....................................... 597

Daniel Shanks, Two theorems of Gauss......................... 609

Paul Slepian, On the Lebesgue area of a doubled map ............... 613

Otto Szász and Nelson Paul Yeardley, Jr., The representation of an analytic function by general Laguerre series . ..................... 621

Alan C. Woods, On two-dimensional convex bodies ................. 635 